\title{
Characterization of Surface Species During Benzene Hydroxylation over a NiO-Ceria-Zirconia Catalyst - Supporting Information
}

\author{
Jennifer N. Jocz, Yimeng Lyu, Bryan J. Hare, Carsten Sievers*
}

School of Chemical and Biomolecular Engineering, Georgia Institute of Technology, Atlanta, GA, 30309, United States

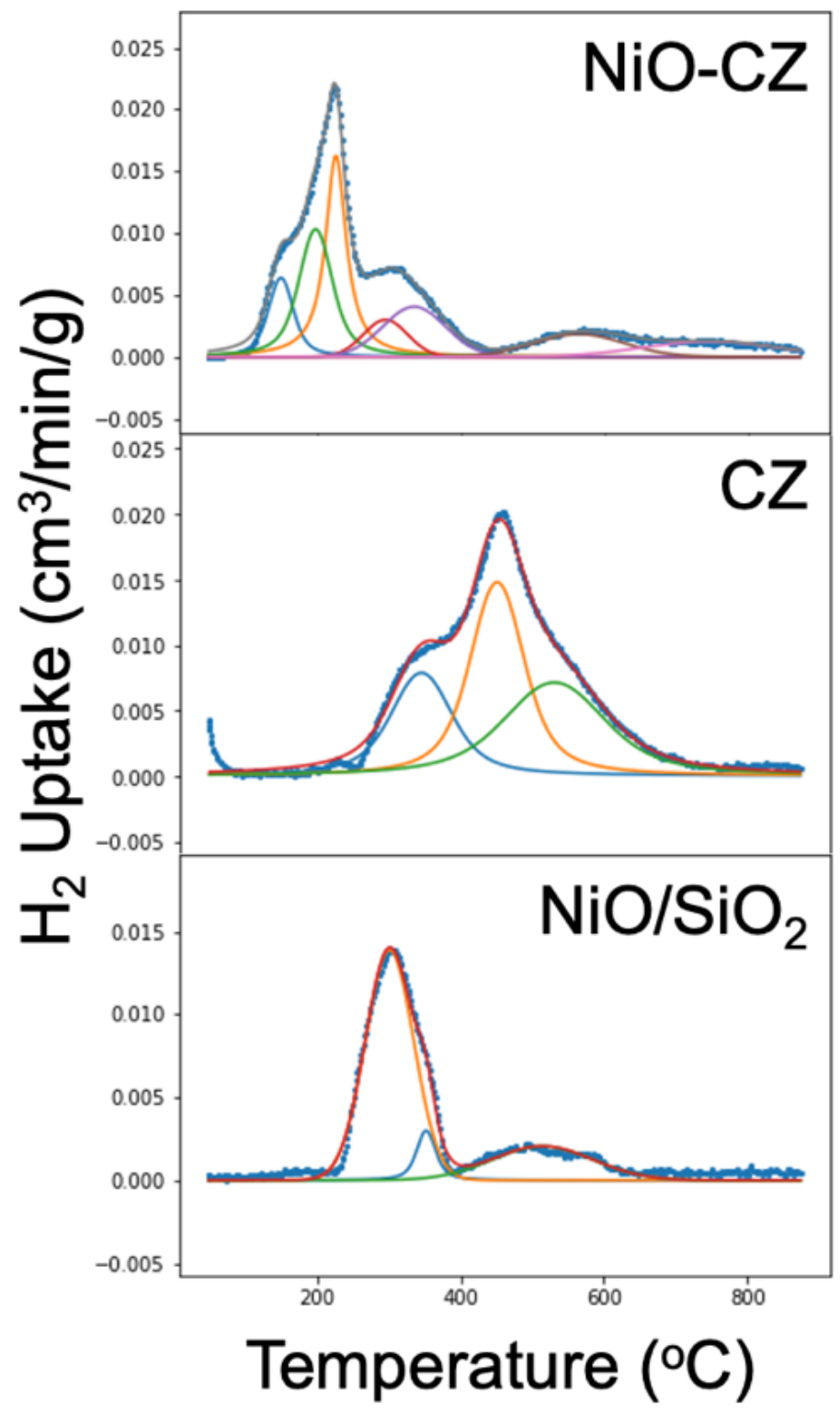

Figure S1: Peak deconvolution of $\mathrm{H}_{2}$ temperature programmed reduction experiments for $2 \mathrm{wt} . \%$ $\mathrm{NiO}-\mathrm{CZ}$ (top), $\mathrm{CZ}$ (middle), and 2 wt.\% $\mathrm{NiO} / \mathrm{SiO}_{2}$ (bottom). 

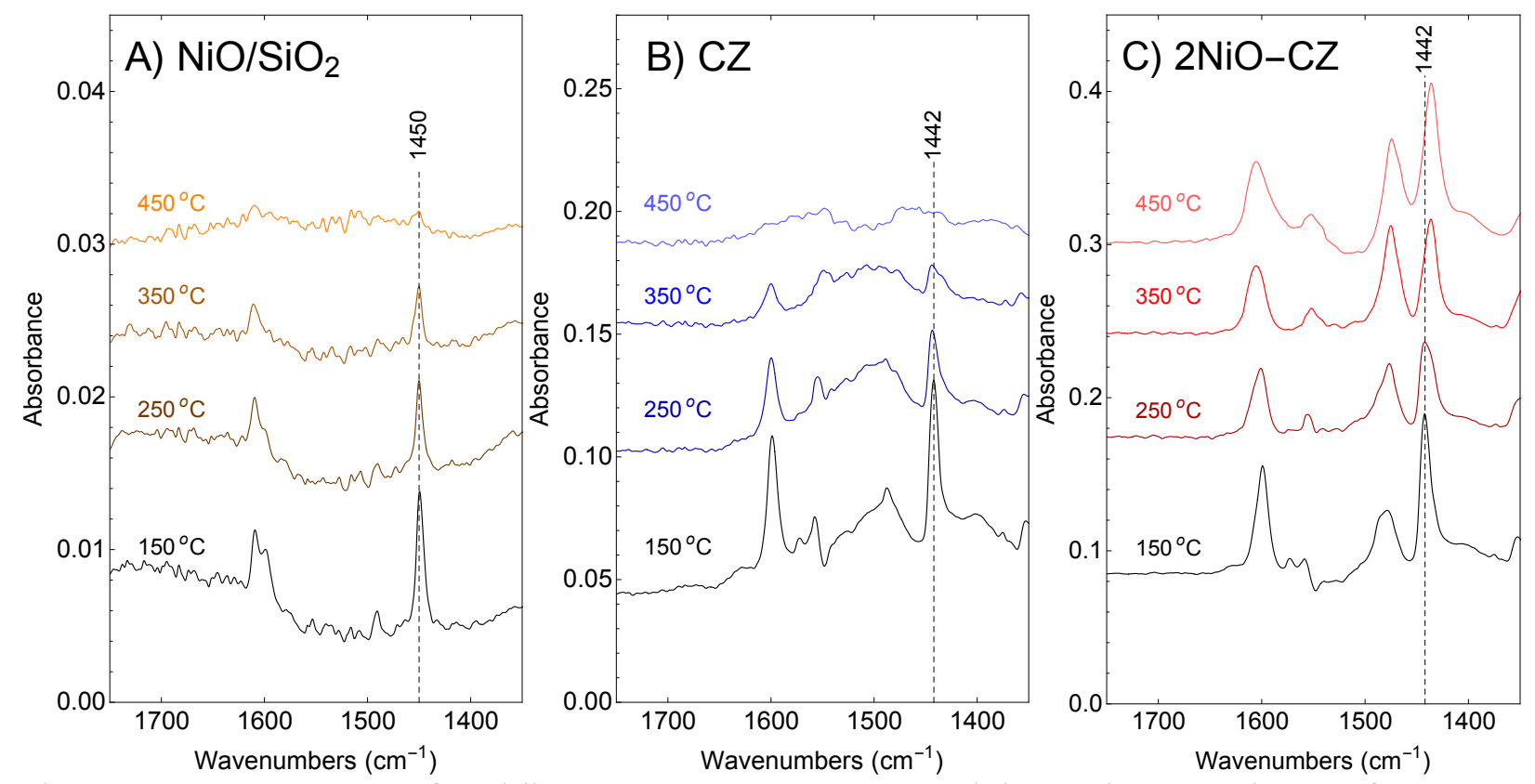

Figure S2: FTIR spectra of pyridine temperature programmed desorption experiments for $2 \mathrm{wt} . \%$ $\mathrm{NiO} / \mathrm{SiO}_{2}(\mathrm{~A}), \mathrm{CZ}(\mathrm{B})$, and $2 \mathrm{wt} . \% \mathrm{NiO}-\mathrm{CZ}(\mathrm{C})$ at $150,250,350$ and $450{ }^{\circ} \mathrm{C}$.
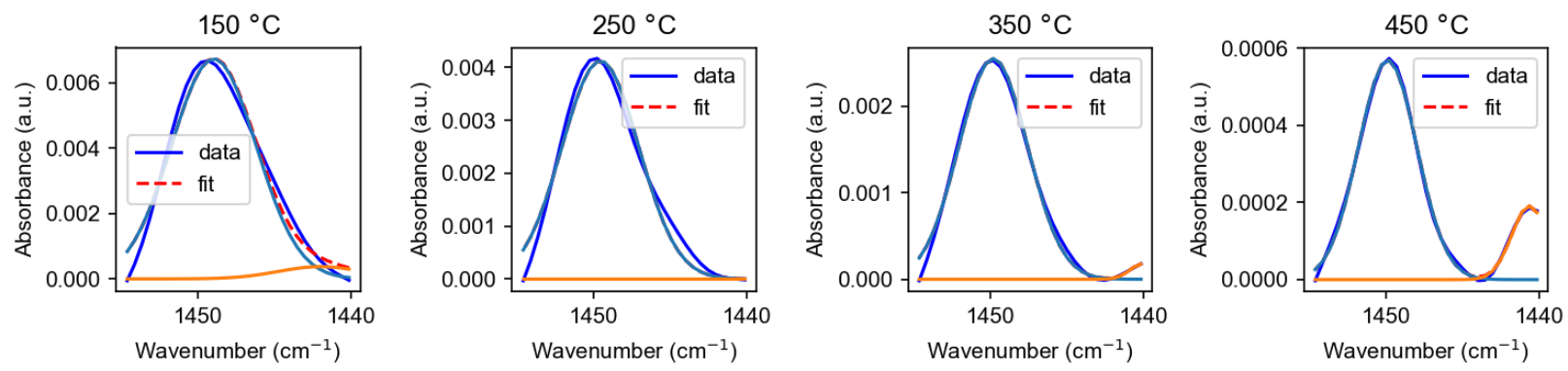

Figure S3: Peak fitting analysis separated the FTIR adsorption peaks for pyridine (gray curve, $1449 \mathrm{~cm}^{-1}$ ) and carbonate (orange curve, $1440 \mathrm{~cm}^{-1}$ ) measured during pyridine temperature programmed desorption on $2 \mathrm{wt} . \% \mathrm{NiO} / \mathrm{SiO}_{2}$ at $150,250,350$ and $450{ }^{\circ} \mathrm{C}$. The carbonate peak resulted from oxidation of adsorbed pyridine.
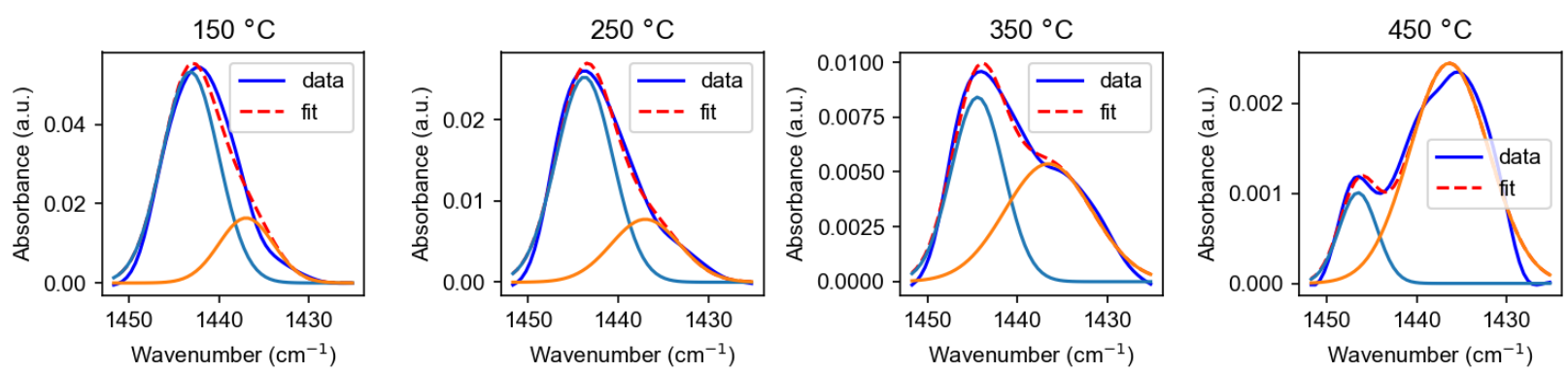

Figure S4: Peak fitting analysis separated the FTIR adsorption peaks for pyridine (gray curve, $1449 \mathrm{~cm}^{-1}$ ) and carbonate (orange curve, $1440 \mathrm{~cm}^{-1}$ ) measured during pyridine temperature programmed desorption on $\mathrm{CZ}$ at $150,250,350$ and $450{ }^{\circ} \mathrm{C}$. The carbonate peak resulted from oxidation of adsorbed pyridine. 

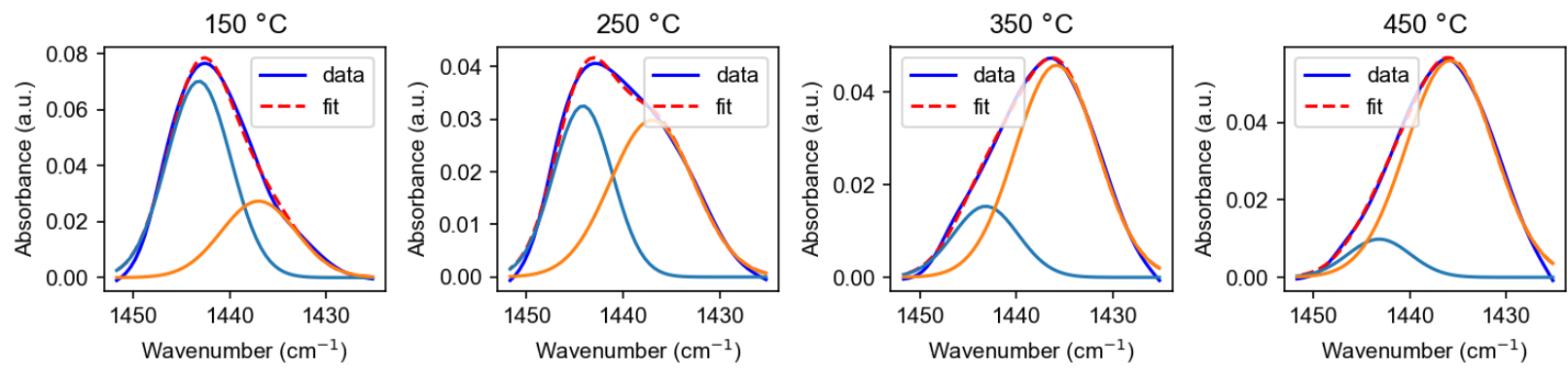

Figure S5: Peak fitting analysis separated the FTIR adsorption peaks for pyridine (gray curve, $1449 \mathrm{~cm}^{-1}$ ) and carbonate (orange curve, $1440 \mathrm{~cm}^{-1}$ ) measured during pyridine temperature programmed desorption on $2 \mathrm{wt} . \% \mathrm{NiO}-\mathrm{CZ}$ at $150,250,350$ and $450{ }^{\circ} \mathrm{C}$. The carbonate peak resulted from oxidation of adsorbed pyridine.

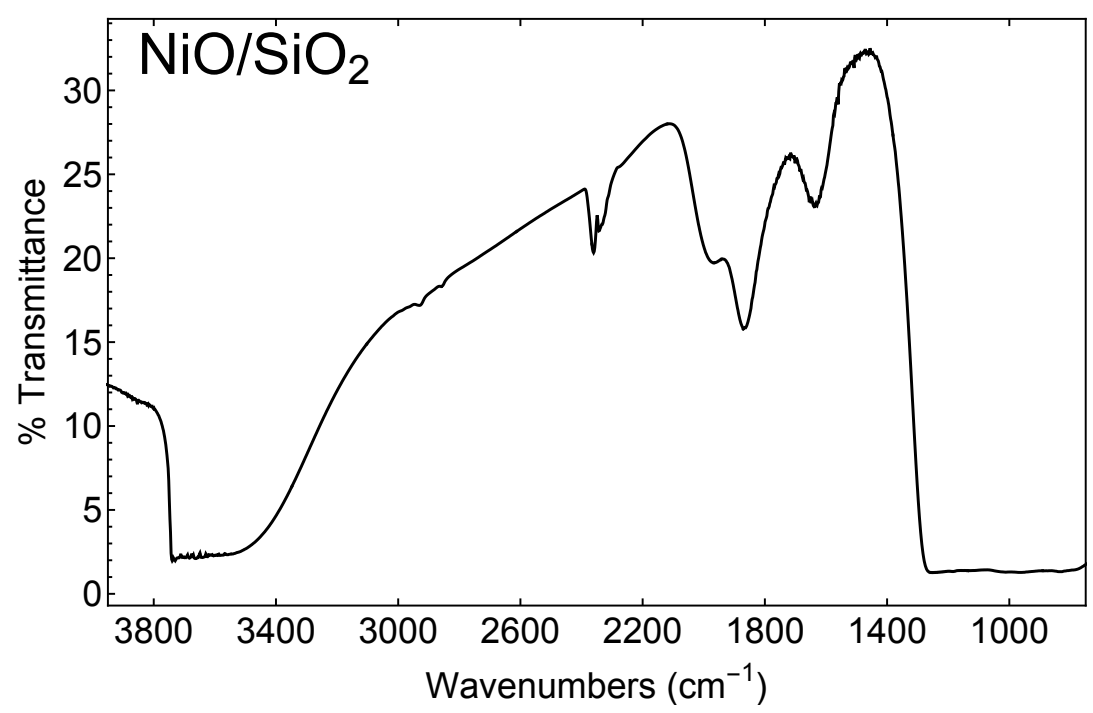

Figure S6: FTIR spectra of $2 \mathrm{wt} . \% \mathrm{NiO} / \mathrm{SiO}_{2}$ at $50{ }^{\circ} \mathrm{C}$ after activation in high vacuum at $450{ }^{\circ} \mathrm{C}$ for $1 \mathrm{~h}$. The small features in the $2900 \mathrm{~cm}^{-1}$ region were identified as a carbonaceous molecule outside of the IR sample cell but located within the beam path, and they were also observed when the sample cell was removed from the path of the beam. 

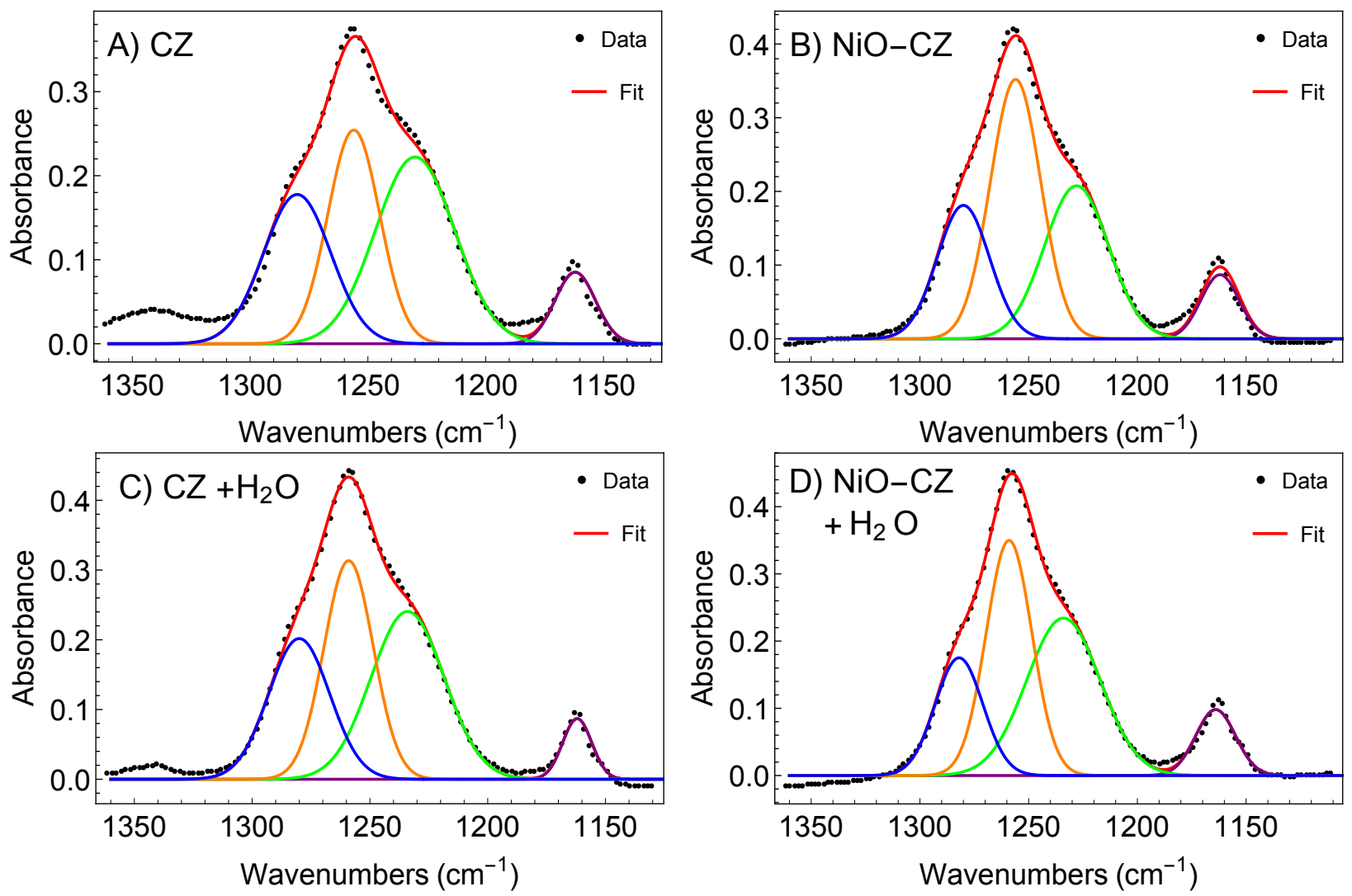

Figure S7: Peak fitting analysis separated the FTIR adsorption peaks for $v(\mathrm{C}-\mathrm{O})$ of un-dissociated phenol (green curve, $\left.1228 \mathrm{~cm}^{-1}\right), v(\mathrm{C}-\mathrm{O})$ of catecholates (orange curve, $\left.1258 \mathrm{~cm}^{-1}\right)$, and $v(\mathrm{C}-\mathrm{O})$ of phenolates (blue curve, $1280 \mathrm{~cm}^{-1}$ ) measured during phenol adsorption at $180^{\circ} \mathrm{C}$. The conditions were: 0.1 mbar phenol on CZ (A), 0.1 mbar phenol on 2 wt.\% NiO-CZ (B), 0.1 mbar phenol followed by 0.2 mbar water (C), and 0.1 mbar phenol followed by 0.5 mbar water on $2 \mathrm{wt} . \% \mathrm{NiO}-$ $\mathrm{CZ}$ (D). Molecule doses were followed by vacuum treatment prior to collecting spectra. 


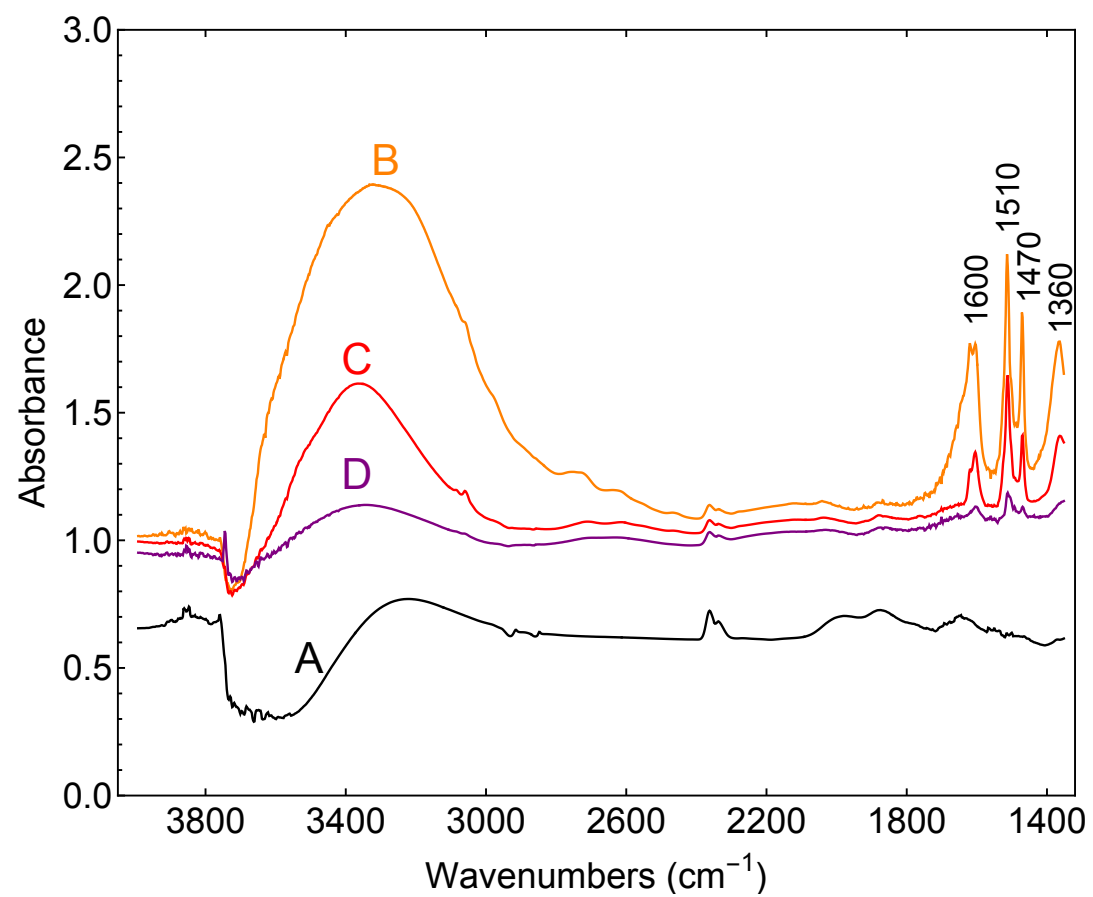

Figure S8: Signal A shows the FTIR spectra of $2 \mathrm{wt} . \% \mathrm{NiO} / \mathrm{SiO}_{2}$ after exposure to an aqueous solution of $0.01 \mathrm{~mol} / \mathrm{L}$ catechol at $50{ }^{\circ} \mathrm{C}$ in high vacuum (conditions identical to those used for catechol adsorption on NiO-CZ and CZ). Signals B-D show $\mathrm{SiO}_{2}$ after exposure to an aqueous solution of $0.1 \mathrm{~mol} / \mathrm{L}$ catechol at $25^{\circ} \mathrm{C}$ and ambient pressure (B), after reaching high vacuum (C), and after $1 \mathrm{hr}$ in high vacuum (D).

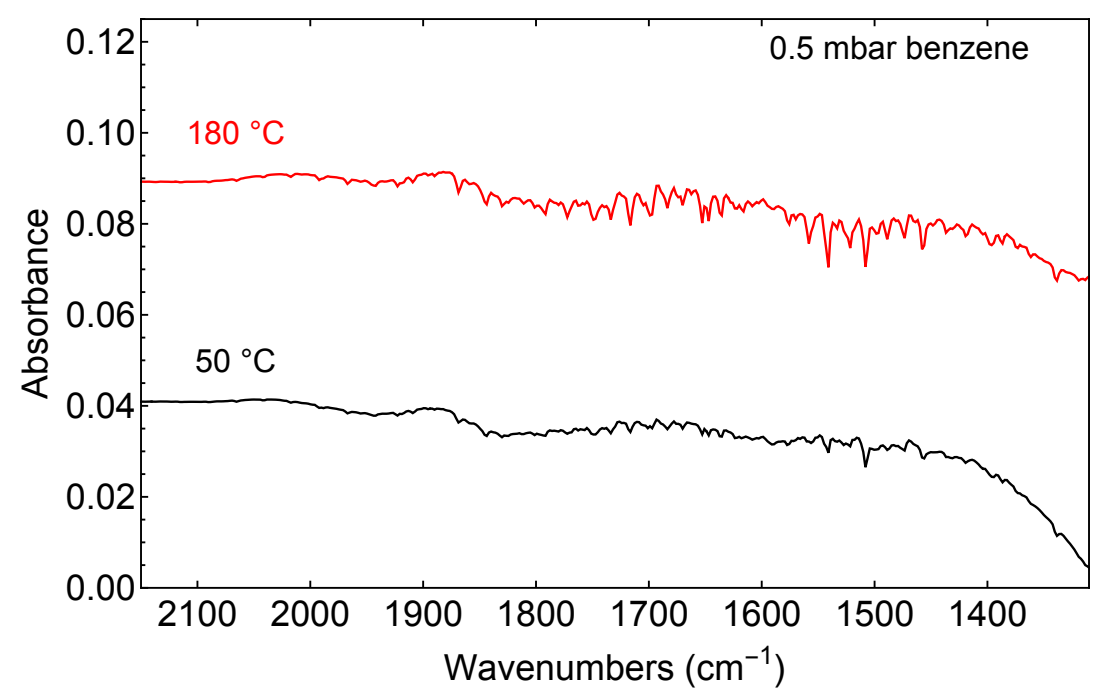

Figure S9: FTIR spectroscopy of $2 \mathrm{wt} . \% \mathrm{NiO} / \mathrm{SiO}_{2}$ after exposure to $0.5 \mathrm{mbar}$ benzene at $50{ }^{\circ} \mathrm{C}$ followed by vacuum and after exposure to 0.5 mbar benzene at $180^{\circ} \mathrm{C}$ followed by vacuum. Spectra are relative to the spectra of activated $\mathrm{NiO} / \mathrm{SiO}_{2}$ at 50 and $180^{\circ} \mathrm{C}$, respectively. 